\title{
Sentidos, prácticas y modificaciones en los informes técnicos del sistema penal juvenil uruguayo
}

Carolina González Laurino*

https://orcid.org/0000-0003-2910-5861

Introducción

Como indican los estudios de García Méndez y Carranza (1990), la minoridad ha oficiado como "producto residual de la infancia" en la indiscriminación de abandono e infracción de los llamados "niños de nadie" antes de pasar a ser los "niños de todos" en el progresivo y nunca alcanzado proceso de responsabilización social (Morás, 2002). La creación de los Tribunales de Menores, impulsados por el Movimiento de los Reformadores, ${ }^{1}$ delimitó la forma de tratamiento judicial de "la cuestión del menor" en Estados Unidos y Europa hasta llegar a América Latina (1921 en Argentina, 1923 en Brasil, 1927 en México y 1928 en Chile) generando consigo una serie de instituciones asociadas y especialistas conexos en la historia de su devenir problemático para las sociedades de principios del siglo Xx. Respaldado en el positivismo de la época, el discurso cientificista elaboró un conjunto de dispositivos tecnológicos

* Universidad de la República, Montevidéu, Uruguai.

1. Originario de los Estados Unidos, el Movimiento de los Reformadores proponía un tratamiento normativo e institucional diferenciado para niños y adultos infractores. Formado por figuras socialmente destacadas de la clase media y alta norteamericana, se concibieron como un movimiento de reforma moral de la infancia pobre, logrando su primer reconocimiento institucional en Illinois en 1889 cuando se crea la justicia especializada para adolescentes. Desde un modelo que partía de la indiferenciación entre abandono infantil y delincuencia, propusieron una serie de regulaciones institucionales destinadas al control de la infancia pobre sancionando conductas anteriormente administradas por medios informales (Platt, 1982). 
de la mano de la biología, la medicina y la psicología criminal que concibieron al niño como "una categoría de sujetos débiles a quienes los instrumentos científicos" habilitaban la previsible detección del delincuente ${ }^{2}$ (García Méndez, 2004, p. 38). La representación social de la potencialidad delincuente de los "niños de la calle" se impone con este espíritu inspirador en el Código del Niño (Ley 9.342, 1934) cuya preocupación estuvo centrada en el control moral de las clases excluidas de la producción social de la riqueza y el consumo (Morás, 2002). Su objetivo de reforma social de los sectores pobres será implementado mediante dispositivos sanitarios y sociales de control, fundamentado en el discurso del "higienismo", que buscaba regular las prácticas cotidianas de alimentación, higiene y reproducción a través de técnicas de control sanitario que promoverían formas de prevención y autocuidado de la población uruguaya a principios del siglo xx (Ortega, 2008).

Como la mayoría de los países latinoamericanos, Uruguay suscribió la Convención de los Derechos del Niño en 1990 (Ley 16.137), pero no es sino hasta 2004, cuando se aprueba el Código de la Niñez y la Adolescencia (Ley 17.823), adaptando la normativa vigente (Código del Niño, Ley 9.342, 1934) a la regulación internacional de la doctrina de la protección integral. De la misma manera que tarda en concretarse la legislación respecto a la niñez y la adolescencia en el país, también lo hace el proceso de discriminación entre las instituciones responsables de regular la protección y la represión a las trasgresiones adolescentes. Es así como recién en 2015 se separa la institucionalidad que atiende la protección de la que regula el cumplimiento de medidas judiciales en casos de infracción (Ley 19.367). Modificando su denominación en cortos períodos de tiempo, ${ }^{3}$ sin cambiar sustancialmente las prácticas arraigadas de la tutela, el Instituto Nacional de Inclusión Social Adolescente (Inisa)

2. Como forma de ilustrar el fenómeno enunciado, Emilio García Méndez trae a colación las palabras del director del "laboratorio de biología infantil de Río de Janeiro inaugurado en 1936", espejo "del centro médico pedagógico de Roma de 1934" que solicitaba la dotación de recursos a efectos de "reunir la información que facilite el conocimiento de la vida de los menores delincuentes o abandonados antes de la práctica del delito..." (Ribeiro apud García Méndez, 2004, p. 34).

3. La institución reguladora de la infancia en el país, creada por el Código del Niño de 1934 fue cambiando su nominación desde el Consejo del Niño (1934), pasando a llamarse Instituto Nacional del Menor (1988) hasta el actual Instituto del Niño y el Adolescente en Uruguay (1990). Más problemática ha sido la institucionalidad encargada del cumplimiento de medidas judiciales que en pocos años modificó su denominación, en una sucesión infructuosa de autoridades que no lograron cambiar su contenido: Instituto Técnico de Rehabilitación Juvenil (Interj), Sistema de Ejecución de Medidas para Jóvenes en Infracción (Semeji), Sistema de Responsabilidad Penal Adolescente (Sirpa) - creado Ley 18.771 (2011), se propone la transitoriedad hasta la creación de un nuevo servicio descentralizado, cuya propuesta de denominación - modificada posteriormente - fue Instituto de Responsabilidad Penal Adolescente (Irpa), sustituido por el actual Instituto Nacional de Inclusión Social Adolescente (Inisa) - que transfiere las competencias del Sirpa y el Semeji mediante la Ley 19.367 (2015). Cf. El País, 12/9/2016. 
es actualmente la institución responsable de la ejecución de medidas judiciales, tanto privativas como no privativas de libertad. Estas últimas se encuentran bajo la órbita del Programa de Medidas Socioeducativas y Mediación (Promesem) que convenia con cuatro organizaciones de la sociedad civil y opera únicamente en Montevideo, área metropolitana y un departamento del Litoral Norte del país. En el resto del país las medidas judiciales se desarrollan en la misma institución de protección a la infancia, lo que estaría dando cuenta de que la indiscriminación protección-represión resulta una asignatura pendiente en Uruguay. Si la institución de aplicación de medidas judiciales resulta compleja, la justicia especializada en adolescentes no lo es menos, ya que se encuentra centralizada en los cuatro juzgados que actúan en Montevideo, por lo que, en el resto del país se trabaja de manera conjunta en materia penal juvenil y adultos sin personal especializado.

Este artículo enfoca su mirada en las prácticas de los discursos de los técnicos del sistema penal juvenil, tanto en su segmento judicial como ejecutivo, partiendo del supuesto que las palabras de los especialistas en las áreas social y psicológica, fundamentalmente, influirían de manera condicionante en las decisiones judiciales. De esta forma, como en la doctrina tutelar de la infancia, la lectura que los expertos hacen de la vida de los adolescentes se convertiría en significativa a la hora de analizar judicialmente un mismo hecho trasgresor a la luz de biografías diferenciadas por la escolarización, las primeras experiencias laborales, el consumo de sustancias psicoactivas, pero, fundamentalmente, por la extracción social de donde provienen sus familias de origen, con una responsabilización que estaría operando de manera moralizadora, fundamentalmente, sobre las madres de los adolescentes varones pobres respecto al rol socialmente esperado de cuidadoras (Batthyány, 2008).

\section{Metodología}

Con el propósito de dilucidar el entramado de los discursos que dieron lugar a las prácticas de los informes técnicos en las instituciones de castigo en Uruguay la indagación se sustentó en instrumentos de recolección de información de carácter cualitativo empleando material procedente de expedientes judiciales y de entrevistas a abogados, jueces, psicólogos, psiquiatras, educadores y trabajadores sociales.

La muestra estuvo formada por veintiocho expedientes judiciales, seleccionados en forma aleatoria de los archivos de los cuatro Juzgados Letrados de Adolescentes de Montevideo, y por diecisiete entrevistas a los técnicos del sistema penal juvenil en los segmentos judicial y de ejecución de medidas socioeducativas privativas y no privativas de libertad implementadas por el Estado y organizaciones de la sociedad civil en Montevideo, Canelones, San José y Salto. 
La investigación fue avalada por el Comité de Ética de la Facultad de Psicología de la Universidad de la República y contó con las correspondientes autorizaciones en las instituciones públicas involucradas. El procedimiento sigue las exigencias deontológicas para el uso de la información, preservando la confidencialidad, privacidad y el anonimato de las personas participantes. Las entrevistas fueron realizadas mediante consentimiento informado firmado, respetando la autonomía y voluntad de la participación en el estudio (American Psychological Association, 2017).

\section{Valoraciones judiciales de los informes expertos}

En primer término, resulta pertinente indagar en el discurso de los operadores judiciales para conocer las expectativas que tienen sobre los informes técnicos que reciben del sistema ejecutivo con el propósito de visualizar la correspondencia entre unos y otros relatos.

Los discursos de jueces y defensores colocan el énfasis en la especialización de los técnicos que serían portadores de un conocimiento del que ellos carecen para caracterizar al adolescente, a la vez que valoran el tiempo que los técnicos dedican a indagar en el entorno sociofamiliar del adolescente tanto en medio abierto como en los centros en los que se desarrollan las medidas privativas de libertad. Los informes expertos tanto como las entrevistas dan cuenta del contexto social de procedencia del adolescente, así como de las características físicas, psicológicas, médicas, psiquiátricas y educativas de los adolescentes que cumplen medidas judiciales. Esta información es reconocida y apreciada por defensores, jueces y fiscales al momento de dictaminar el destino del adolescente, más allá de la infracción cometida.

Asimismo, confían en el acercamiento de los técnicos, especialmente los psicólogos, en la apreciación de las valoraciones del adolescente respecto a la infracción por la que ha sido judicializado, con especial énfasis en la pregunta por el arrepentimiento por el acto cometido, así como respecto a sus ingresos anteriores al sistema. La información acerca de las faltas o ingresos a prisión de familiares del adolescente, también constituyen datos preciados por los defensores públicos y los jueces entrevistados como estrategia para determinar el carácter y el monto de la pena en una sentencia judicial con independencia de la infracción analizada.

Hay un primer abordaje de cuando el chico ingresa con reflexiones sobre las entrevistas que se tuvo con la familia, qué actividades tiene el joven y qué actividades tiene la familia, si ya ha tenido ingresos anteriores al sistema. Después, toda la visión que puede tener un psicólogo en una entrevista [...] en cuanto a la percepción de determinadas cuestiones vinculadas a la infracción - si asumió la [responsabilidad], si no la asumió - desde el punto de vista psico- 
lógico y, desde el punto de vista social. Los técnicos, mediante entrevistas, elaboran informes que, desde mi punto de vista, [son] suficientes [...] como para que uno se pueda hacer una composición del lugar y que termina con determinadas recomendaciones vinculadas al adolescente. (Defensor de Juzgado Letrado de Adolescentes de Montevideo).

Como contrapartida a las expectativas judiciales, el relato de los entrevistados que trabajan en el segmento ejecutivo confirma lo que los técnicos del Poder Judicial esperan de los informes de los técnicos, explicitando que se refieren a la configuración e historia familiar, contexto de vulnerabilidad social, dificultades psicológicas, así como la descripción del funcionamiento cotidiano en el régimen de encierro tanto como en las medidas en medio abierto.

[En los informes] se da cuenta de su actuar, de cómo se encuentra el adolescente, si cuenta o no con apoyo familiar, de cómo es su estructura familiar, si es con un contexto muy vulnerable o no, si tiene muchas dificultades a nivel endógeno. Después, es de orden dar cuenta de cómo es su funcionamiento dentro del centro, la vida cotidiana, si va al liceo, si va a la escuela, si va a talleres. (Educadora social. Privación de libertad. Inisa).

De acuerdo con las palabras de los entrevistados, los técnicos que trabajan en el sistema de ejecución de medidas socioeducativas informan al sistema judicial acerca de la vida cotidiana del adolescente, a la vez que realizan sugerencias y recomendaciones. Quienes reciben esos datos sobre la conducta adolescente durante el cumplimiento de la medida - fiscales, defensores y jueces - utilizan la información como insumos de trabajo, retomando las solicitudes técnicas que se convierten en instrumento para determinar la permanencia en régimen de encierro, tanto como para proponer modificaciones en las medidas privativas de libertad a medio abierto.

La influencia que los informes de los especialistas tienen sobre la justicia penal juvenil son bien conocidos y asumidos como tales por los entrevistados, ya que según algunos enunciados, sus palabras son tomadas en los procesamientos acusatorios y en las sentencias judiciales como argumentaciones técnicas para reforzar argumentos jurídicos o para inclinar la balanza hacia la privación de libertad cuando el adolescente aparece solo en el Juzgado sin respaldo familiar ni social, tal como se ha descripto en el proceso de selectividad del sistema penal juvenil. ${ }^{4}$

4. El proceso de selectividad del sistema penal juvenil ha sido analizado como el complejo mecanismo mediante el cual los transgresores adolescentes varones pobres son captados por el sistema de justicia, mientras que las transgresiones de los adolescentes de clase media son procesadas por otros mecanismos sociales que no suponen procesamientos judiciales. Existe amplia bibliografía que ha dedicado esfuerzos a estudiar el fenómeno, que forma parte de un proceso más amplio de criminalización de la pobreza, 
He aprendido, a lo largo del tiempo, a limitarme en los informes al "cumplimiento - no cumplimiento" y al final de la medida si quedó integrado, si se pudo trabajar la dimensión del delito, pero no poner muchas cosas. Porque ¿sabés que me pasaba? Me pasó en una época - al inicio que [hacía] muchos informes - [que] eran tomados por los jueces como justificación. Una vez dije que el chiquilín no tenía una familia, no había nadie que se hiciera cargo, una soledad tremenda. Resulta [que otro adolescente] que había cometido el mismo delito y tenía su familia sale con libertad asistida y a este que no tenía familia lo privan de libertad. Entonces, te das cuenta de que, no lo estás privando la libertad por el delito, lo estás privando de libertad por no tener familia. [...] A partir de ahí soy más cuidadosa. (Coordinadora técnica. Organización de la sociedad civil).

La serie de medidas punitivas a las que alude el Código de la Niñez y Adolescencia (Ley 17.823, 2004) son concebidas como medidas socioeducativas. Como sostienen Lima y Alvarez en el análisis de los informes técnicos en un centro cerrado de adolescentes trasgresores de sexo masculino en San Pablo clausurado en 2007, resulta complejo concebir la punición vinculada a la educación, lo que genera posiciones ambivalentes en los técnicos que desarrollan diferentes herramientas socioeducativas para cumplir el ambiguo propósito de las medidas judiciales 5 (Lima \& Alvarez, 2018, pp. 235-236).

La contradicción del castigo mediante la educación ostenta larga trayectoria histórica en el país, con la idealización de los establecimientos rurales que traerían

por lo cual se mencionarán solo algunos autores del Cono Sur de América Latina que han trabajado el tema. Al respecto cf. Daroqui \& López, 2012; García Méndez, 2011; 2017; García Méndez, Vázquez Jiménez \& Otero, 2019; Guemureman, 2011; Leal \& Macedo, 2019; Leopold, 2014; Morás, 2002, 2016; Uriarte, 1999, 2006; Zaffaroni, 1989; Zaffaroni, Alagia \& Slokar, 2002.

5. Como refieren los autores en el caso brasileño, en Uruguay también es posible visualizar una concepción de la educación social en contextos de encierro que fuera desarrollada, en primera instancia en el país por el Centro de Estudios y Formación (Cenfores) del Instituto Nacional del Niño y el Adolescente en Uruguay (Inau), que actualmente constituye una carrera terciaria no universitaria del Instituto de Profesores Artigas (IPA) dependiente de la Administración de Educación Pública. En esta corriente de pensamiento se destacan los trabajos del educador social Diego Silva Balerio. En un pionero trabajo publicado en 2001, el autor concluía manifestando; "entiendo que es posible una acción educativa liberadora en contextos adversos como los descritos. No es un trabajo sencillo, ya que expone tanto el cuerpo del educador como su capacidad intelectual para buscar constantemente alternativas que propicien la autonomía y la conciencia crítica de las y los jóvenes" (2001, p. 253). En 2015, en el Grupo de trabajo de adolescentes en el marco de la elaboración de una Estrategia nacional de educación para personas en conflicto con la ley penal (cuya síntesis fue publicada en 2016), Silva analiza la desprofesionalización de la función socioeducativa, las limitaciones de los dispositivos locativos pensados para la seguridad y la evitación de fugas de los establecimientos juveniles en el Inisa que, junto a otras variables generan coaliciones conceptuales y metodológicas en la tarea socioeducativa en contextos de encierro en Uruguay. 
consigo hábitos saludables a los adolescentes alojados con fines de reeducación social. En el mismo sentido, tanto la legislación vigente como los discursos especializados en la materia parecerían nostálgicos de las antiguas granjas rehabilitadoras para los adolescentes indisciplinados (González Laurino \& Leopold Costábile, 2013).

Las estrategias de moralización de los trasgresores han vuelto una y otra vez a lo largo de la historia a la educación de oficios manuales, de valores sociales, de hábitos de higiene y trabajo, de cumplimiento de rigurosos horarios para la realización de las tareas de la vida cotidiana (Leopold Costábile, 2002; Abal, Cheroni \& Leopold, 2005), todo esto en el contexto de la vida campestre que aparecería ennoblecida en sus propósitos de transformación social del trasgresor adolescente. La dignidad moral parecería estar representada en el arduo trabajo del hombre de campo que se presenta como ideal a seguir para estos jóvenes provenientes de los suburbios urbanos (Guerra Henriques, 2014).

Así como, en palabras de Garland, "el destino del castigo es nunca «tener éxito» pleno" (2006, p. 334) la respuesta al infractor resulta ser la reeducación moralizadora con propósitos de transformación de la persona en un ser adaptado y socialmente productivo, alejado del "vicio" y las conductas reprochables mediante las que, en función de su análisis biográfico, parecería haberse conducido hasta el hecho juzgado.

No obstante, la "ideología del tratamiento" - como la llama Christie - ha sido sustituida por la "teoría de la prevención general o la disuasión", que no actúa inmediatamente luego de consumado el hecho, sino a través de una serie de mediaciones burocráticas tiempo después, lo que hace que nadie pueda eludir el castigo por un comportamiento inapropiado regulado según tipos específicos (Christie, 1988). Aunque el tratamiento resocializador no ha logrado los resultados esperados, esta modalidad de pensar la cuestión penal juvenil continúa en la agenda de la política penal juvenil uruguaya. No obstante, parecería infructuosa la tarea de habilitar procesos de transformación personal mediante la imposición de rutinas rigurosas, hábitos de higiene, trabajo y estudio, como ha perseguido, de manera insistente a lo largo de su historia, el sistema penal juvenil uruguayo (González Laurino \& Leopold Costábile, 2013).

"Si tú no cumplís, nosotros informamos la verdad al juez"

Inclusive en las prácticas "más amables" de las medidas socioeducativas no privativas de libertad parecerían reconocerse mecanismos de control disciplinario que se traducen en la espada de Damocles de la medida de privación de libertad en los relatos con los adolescentes que los entrevistados refieren en sus discursos de intimación al cumplimiento de la medida judicial. 
Si un adolescente no cumple, nosotros enviamos un informe y se pide el reencuadre de la medida. Entonces se le dice: “- Bueno, si vos no cumplís la medida, nosotros tenemos que informar, porque el juez te obliga a ti a cumplir y a nosotros a hacer el seguimiento y la ejecución de las medidas, estamos los dos obligados, así que, si tú no cumplís, ${ }^{6}$ nosotros informamos la verdad al juez" (Psicóloga. Organización de la sociedad civil).

En el caso de esta jueza nueva, por primera vez, cuando yo le mando un informe, diciendo que un chiquilín no cumple, convocó al adolescente, a la mamá y a mí a la audiencia de reencuadre y le dijo: “- Yo no puedo permitir que tu no cumplas con esto, porque esto es una disposición penal, así que tú vas a tener que cumplir como sea, o cumplís ahí, viviendo en tu casa, yendo a trabajar o te tengo que privar de la libertad”, y dijo privar de la libertad, le dijo: “- ¿A dónde vas a ir?”, “- A un hogar”, y ella le dijo: “- No es un hogar, es una cárcel, de menores, pero es una cárcel, no es un hogar, hogar es el que tenés en tu casa”. Por primera vez, el discurso de la jueza fue [determinante]. Entonces, le dijo: “- No, vas privada de la libertad, yo soy responsable que lo que tu hiciste no quede sin respuesta penal”. Bueno, al final dijo que iba a cumplir y está viniendo. (Psicóloga. Organización de la sociedad civil).

Esta estrategia de solicitud de una "audiencia de reencuadre" ante incumplimientos de medidas no privativas de libertad - que el sistema judicial no estaría respondiendo en tiempo y forma en el interior del país - parecería ser un reclamo de valoración de la medida judicial no privativa de libertad en la percepción de los técnicos en el caso en que el adolescente no se presente voluntariamente o no asista con la regularidad requerida por el dispositivo. No obstante, el relato de la entrevistada que, conscientemente buscaría generar acuerdos con la medida socioeducativa en la adolescente, parecería operar como amenaza ante el incumplimiento en la respuesta de la jueza quien - de acuerdo con el relato de la entrevistada -, le advierte sobre la posibilidad de la privación de libertad.

Por otra parte, sobre todo desde los Juzgados Letrados del interior del país, se estaría demandando una forma específica de redacción los informes técnicos, como si la "opinión experta" requiriese de un lenguaje especializado que los educadores, que trabajan directamente con el adolescente, no estuvieran en condiciones de proporcionar. Los relatos estarían dando cuenta de una suerte de "traducción” de las sencillas

6. En el uso informal del lenguaje en Uruguay se utiliza la expresión "vos" al igual que "você" en Brasil en la segunda persona del singular. No obstante, conviven en el país la utilización del "tu" (sobre todo en el departamento de Rocha) con el "vos” a pesar de que no se sostiene la conjugación verbal del tú en los verbos que continúan la conjugación de la expresión "vos” como segunda persona del singular. 
expresiones del personal de trato directo al lenguaje psicológico mediante palabras especializadas que parecerían recubrir lo visible mediante procesos crípticos de análisis e interpretación, devolviendo a los expertos en derecho un otro a ser juzgado.

Informes técnicos sobre responsabilización del adolescente en la infracción

Los operadores del sistema de ejecución de medidas también informan acerca del proceso de reflexión del adolescente sobre la infracción por la que fue judicializado, disposición que se encuentra especificada en el Código de la Niñez y la Adolescencia (Ley 17.823, 2004) y sobre la que los técnicos del sistema judicial esperan opinión experta.

El sistema judicial espera que los adolescentes asuman la carga de la responsabilización por la trasgresión a la ley penal, para lo cual confían en los informes técnicos del sistema de ejecución de medidas. Sin embargo, en los informes expertos que surgen de la muestra de expedientes judiciales analizados, la idea de "responsabilidad" aparece como una colección de enunciados vaciados de contenidos históricos y contextuales en referencia a la trayectoria social de estas familias conceptualizadas como "abandónicas" (Uriarte, 2006), con padres enunciados como irresponsables en las tareas de cuidado y puesta de límites de sus hijos (Ávila Navarrete, 2017), en donde el grupo de pares juega un rol importante en la explicación de la comisión de una serie de trasgresiones que van llevando al adolescente por el camino del crimen hasta el hecho juzgado (cf. Donzelot, 2008; González Laurino \& Leopold Costábile, 2017).

Estas piezas discursivas que constituyen los dictámenes expertos parecerían constituirse en una repetición de enunciados descalificatorios del lugar social y familiar de estos sujetos, careciendo del contexto de condicionamientos socioeconómicos y culturales en su descripción de actitudes y conductas adolescentes. En este sentido, se coloca bajo la lupa una trayectoria biográfica interpretada en términos individualizantes (Beck, 2001), como si el sujeto fuera capaz de manejar, por sí mismo, el deterioro social que la pobreza deja impresa en los seres más vulnerables de una sociedad de clases.

El análisis de estos informes expertos habilita a pensar en un solo sujeto que se repite sin tiempo, lugar, ni origen social, generando la sensación de que su elaboración consiste en copiar y pegar caracterizaciones similares como si las trayectorias de estos adolescentes fueran pasibles de ser explicadas mediante un único discurso estereotipado (González Laurino \& Leopold Costábile, 2017).

Si los informes técnicos a la justicia revisten la carga de la responsabilización individual, propiciando el "arrepentimiento" del adolescente que es conducido por la 
justicia penal juvenil a la "confesión”, prevista como atenuante en el proceso, aparecen algunos relatos que no colocan el énfasis en la responsabilidad adolescente, sino en la promoción de su capacidad de reflexión que los conduciría al autoconocimiento. Este ejercicio de estímulo de expresión de los afectos involucrados en el proceso mediante la palabra estaría habilitando a pensar en la concepción foucaultiana de parrhesía que el autor rescata de los antiguos filósofos griegos y romanos que llevarían a sus discípulos al ejercicio del conocimiento de sí (Foucault, 2001, 2009, 2010).

\section{Percepción experta de inutilidad de informes tecno-burocráticos}

Si bien la tarea de elaboración de informes a la sede judicial puede ser tomada con entusiasmo por algunos operadores, para otros, resulta una experiencia tediosa e infructuosa, ya que, de acuerdo con sus relatos, las consideraciones técnicas expresadas en estas piezas escritas y dirigidas al juez no son leídas ni apreciadas si resultan excesivamente largas en sus argumentaciones.

\footnotetext{
Donde yo estoy parecemos más un técnico burócrata que hace informes para un legajo que nadie lee, porque ni siquiera el juez ni el defensor los lee. (Psicóloga. Promesem. Inisa).

Los informes son muy escuetos porque si vos al juez le das un informe de cuatro hojas no lo lee porque tiene muchos casos. Es lo que he escuchado. Tienes que ponerle bien concreto "educación física, participa en los talleres, bien, mal, más o menos" es muy escueto. Se pone sobre la familia: quién viene, quién no viene, bien especifico, dos oraciones como mucho. El juez quiere buscar esto y lo encuentra. (Profesor de Educación Física. Privación de libertad. Inisa).
}

Pese a la referida influencia de los informes técnicos en las entrevistas de los operadores de la justicia juvenil en el procesamiento - tanto en las argumentaciones del fiscal, el defensor y el juez - surge la percepción generalizada entre los técnicos acerca de la escasa influencia de un trabajo que se advierte como poco reconocido y burocratizado. Por lo expuesto, esta apreciación técnica no parecería corresponderse con las entrevistas realizadas a los operadores judiciales ni con los expedientes analizados que, como ya fuera indicado, retoman las palabras de los expertos en las argumentaciones de los escritos jurídicos.

Es posible relacionar estas apreciaciones técnicas devaluadas con lo que Michael Lipsky (1983) denomina street-level bureaucracy en que la aplicación de la ley depende de las creencias de un tipo de funcionarios ubicados en el último eslabón de la cadena burocrática. De esta manera, afirma el autor, se despliegan estrategias individuales con legitimación de sus pares como formas de responder a las demandas del trabajo 
cotidiano. Utilizando el concepto de Lipsky (1983) y las herramientas conceptuales de Pierre Bourdieu $(1987,1994)$, el equipo de investigadores formado por Halliday, Burns, Hutton, McNeill y Tata (2009) encuentran que los trabajadores sociales del área judicial experimentan sentimientos de desvalorización frente a otras profesiones históricamente reconocidas del campo jurídico. En el caso uruguayo, sin embargo, similar planteamiento involucraría otras profesiones y no se correspondería con la percepción manifestada por los técnicos judiciales durante las entrevistas, por lo menos, a nivel manifiesto.

Resistencias al nuevo protocolo de informes a los Juzgados Letrados de Adolescentes

Entre 2016 y 2018, Unicef, Uruguay contrató a una especialista latinoamericana Maria Gracia Morais de Ramírez (2018) - para la elaboración de un nuevo protocolo de informes técnicos que sería elevado por el sistema de medidas no privativas de libertad a los Juzgados de Adolescentes de Montevideo. La experta trabajó en forma conjunta con todos los actores nacionales e internacionales en la aprobación de un documento que culminó en 2018 con indicaciones concretas para la elaboración de los informes dirigidos al juez. De esta forma se aprobó lo que se denominó un Plan de Atención Individual que da cuenta del plan de trabajo acordado con el adolescente al inicio de la medida, así como sus avances y grados de cumplimiento. Los informes de las distintas áreas que antes eran elevados al juez quedan, a partir de 2016 en la carpeta del adolescente en Promesem del Inisa.

La modificación supuso que los nuevos dispositivos de información judicial estuvieran adscriptos a las tareas de un educador que oficia como referente en el trato cotidiano y directo con el adolescente. Sin embargo, esta figura del educador ha sido históricamente devaluada institucionalmente, posee escasa formación y proviene de los centros de privación de libertad, con síntomas de agotamiento físico y afectivo después de pasar por los espacios más desgastantes de los dispositivos de castigo. Este pasaje por los centros de encierro habría dejado marcas indelebles en los operadores más antiguos habituados al uso de prácticas deterioradas en el trato directo con los adolescentes que, probablemente, tiendan a replicar en contextos más abiertos pese al estímulo que reciben de las autoridades a la formación permanente y al reciclaje profesional que las medidas no privativas de libertad estarían demandando (González Laurino \& Leopold Costábile, 2013).

Los relatos de operadores técnicos, que acostumbraban a elevar sus pareceres al juez, oscilan entre la desconfianza y una suerte de oposición pasiva que tienen que aceptar de una institución verticalizada. Las sospechas van desde "resulta más barato contratar educadores que técnicos especializados" hasta la expectativa de la reacción 
negativa de los operadores judiciales, pasando por un cuestionamiento velado a la capacidad del educador que toma insumos técnicos para elaborar el Plan de Atención Individual e informar avances y retrocesos en su cumplimiento.

La dirección de Promesem, que participó activamente en el proceso de elaboración del plan de trabajo individual, supuso un severo cuestionamiento a las prácticas anteriores de elaboración de informes técnicos y operó pese a la resistencia manifestada tanto por los profesionales como por los operadores judiciales. “- No es fácil criticar el propio informe”, dirán las autoridades respecto a las piezas escritas que expresaban estereotipos sociales que influenciaban el destino de los adolescentes. No obstante, la disposición de poner en manos de un educador social escasamente formado y con problemas de burnt out en el sistema, no parecería haber sido la solución más adecuada para resolver el problema.

\section{Consecuencias de la aplicación del Código de Proceso Penal en la justicia juvenil}

El nuevo Código de Proceso Penal (Ley 19.293, 2014), que comenzó a implementarse en diciembre de 2017, implicó una serie de modificaciones que van desde la oralidad de audiencias grabadas hasta la centralidad de la figura de la fiscalía en la transformación hacia un proceso acusatorio. En el marco de una audiencia judicial, con lenguaje especializado y actores extraños, el adolescente puede, en esta nueva modalidad, identificar a su defensor y a las distintas figuras presentes en la audiencia. En el anterior sistema de procesamiento penal el adolescente conocía a su defensor en la instancia de la audiencia y, ante una estructura argumental opaca, le era imposible reconocer los roles jurídicos de los actores presentes en la sala, con las consecuencias implicadas en su defensa y sentencia.

El cambio en la forma de tramitación judicial que trajo el Código de Proceso Penal ha supuesto una modificación sustantiva en la regulación de la justicia penal juvenil debido, entre otras cuestiones, a la importante disminución de los adolescentes en el sistema penal juvenil (Tenembaum, 2019). No obstante, esta reducción del punitivismo penal en la gestión de la cuestión de la infracción adolescente no fue celebrada de la misma forma por todos los actores de la sociedad uruguaya. Mientras que la fiscalía resaltaba la disminución de la presión sobre el sistema de ejecución de medidas judiciales, por otra parte, se denunciaba la "benevolencia" para con las trasgresiones sociales y la disminución en la eficacia de la defensa social. Atacada por la derecha política, la fiscalía se vio forzada a defender los beneficios del sistema acusatorio con cifras procesales que pretendían mostrar que la eficiencia del sistema de procesamiento penal en jóvenes y adultos no había disminuido (Fiscalía General de la Nación. Uruguay, 2018, 2019). 


\section{Discusión}

Como argumenta Foucault (2000) en su clase del 15 de enero de 1975 en el Collège de France, los informes no proceden estrictamente del análisis y el método científico ni se rigen por el modelo del discurso jurídico. No obstante, se apoyan en un paradigma de la verdad con consecuencias sobre la vida de los jóvenes que se colocan bajo la mirada del clínico. El autor analiza el informe experto que "se refiere mucho más a ese contexto de existencia, de vida, de disciplina del individuo, que al acto mismo que ha cometido y por el cual se traduce frente al tribunal de menores" (Foucault, 2000, p. 47). La reflexión foucaultiana muda en el debate uruguayo - ya saldado en términos jurídicos, aunque en la práctica del ejercicio de la justicia penal no se aplique como tal -entre el derecho penal de acto y el derecho penal de autor. De acuerdo con el Código Penal (Ley 9.155, 1933), el Uruguay juzga exclusivamente actos específicamente indicados en la letra de la ley. En la práctica, no obstante, en el sistema penal de adultos y, más aun, en el sistema penal juvenil, los procesamientos y sentencias están más relacionados con la totalidad de la vida de la persona que con el acto cometido, por lo que, ante un mismo hecho infraccional, el tipo de procesamiento y sentencia puede resultar diferente (González Laurino, 2014).

Como indica Foucault, mediante los informes técnicos, los procesos judiciales habilitan la elaboración de un doble juicio sobre la conducta trasgresora y sobre la persona del infractor. Por un lado, el análisis jurídico del acto determina la culpabilidad en la trasgresión a la norma penal, lo que, en términos jurídicos se denomina el "injusto", sobre el que ha tematizado Carlos Uriarte (2013) en el caso uruguayo. Por otra parte, el estudio de lo que se consideran determinaciones biográficas del adolescente que lo vinculan a ámbitos familiares y sociales deteriorados habilitarían la conclusión de la ambigua noción de peligrosidad que queda impresa en el legajo del sujeto. En este recuento de la sucesión de acciones sin infracción, el experto estaría percibiendo predisposiciones individuales a las conductas trasgresoras en los antecedentes biográficos, conformando lo que el autor ha denominado el doble psicológico del delito que se rastrea en la personalidad del infractor (Foucault, 2000, pp. 28-35).

Es por este motivo que el juez solicita el informe técnico con énfasis en la biografía del sujeto, comprobando, de manera circular, que, en sus antecedentes personales, en la interpretación patologizada de su vida familiar, en el contexto socioeconómico de procedencia y en sus vínculos entre pares, radicarían las causas del accionar del adolescente en el acto infractor.

Tanto en las entrevistas a los operadores judiciales como a los técnicos del sistema de ejecución de medidas socioeducativas surge la expectativa del relato de la trayectoria biográfica del adolescente objeto de examen experto que explicaría, 
mediante las peripecias de su socialización primaria y secundaria la inclinación a la trasgresión normativa. Se explica así el cuestionamiento a los informes técnicos como piezas iguales entre sí, con una tendencia a la repetición de las mismas categorías estigmatizadoras sobre la población adolescente que el nuevo modelo de informe a la sede judicial estaría intentando modificar, explicitando únicamente el grado de cumplimiento de un plan de trabajo establecido previamente con el adolescente.

Esta práctica del sistema penal juvenil también estaría avalando el señalamiento de los autores que han indagado en el fenómeno acerca de que el mismo acto puede ser juzgado en forma diferente según quien lo comete. Como fuera señalado, ya a inicios de la década del sesenta por Howard Becker "las leyes específicas están llenas de excepciones" ya que "la aplicación de la norma no es consecuencia automática de una infracción. La aplicación de la ley es selectiva y lo es diferencialmente según tipos de personas en distintos momentos y situaciones" ([1963 $]^{7} 2009$, p. 152; cf. Nota 4).

\section{Consideraciones finales}

Como ha sido indicado en estudios anteriores (González Laurino, 2014), si bien se reconoce la iniciativa del sistema judicial que solicita los informes, tanto las entrevistas realizadas como los expedientes de la muestra seleccionada, dan cuenta de la receptividad de los técnicos en derecho de la biografía adolescente informada por los expertos, habitualmente retomada en las sentencias y en los escritos del fiscal y el defensor, mostrando, de esta forma, la influencia que ostenta el segmento de ejecución de medidas socioeducativas sobre el Poder Judicial. Esta observación alude a la responsabilidad de los expertos del área social y de la salud sobre la decisión judicialmente adoptada.

Los informes técnicos parecerían tener extremo poder sobre las decisiones judiciales con consecuencias sobre la vida de los adolescentes. Pese a algunas lamentaciones de los técnicos que operan en el sistema de ejecución de medidas que refieren desarrollar una actividad burocratizante a través de los informes dirigidos a la justicia - "nadie los lee”, dirán algunos entrevistados -, los expertos saben que su palabra es considerada, por lo que, si realizan una afirmación en lugar de la contraria, la interpretación de los operadores judiciales será distinta y, por tanto, diferente será la consecuencia sobre el destino de los adolescentes. En las consideraciones de fiscales, defensores y jueces la descripción de un adolescente en situación de soledad, sin respaldo familiar, sin soportes educativos o laborales supondrá indefectiblemente la privación de libertad por mayor tiempo, como operaba en la doctrina de la situación

\section{El paréntesis recto refiere a la primera edición de la obra.}


irregular, mediante el argumento de la protección y el control social del indisciplinado (García Méndez, 2004, 2011, 2017).

Resulta interesante el análisis de Ben Crewe (2011) cuando sostiene que la tarea de la rehabilitación ha dejado de ser un tema de relaciones interpersonales para pasar a redireccionarse desde el modelo cognitivo-conductual en el que se privilegia el informe de la conducta de los prisioneros sobre la capacidad terapéutica del trabajo vincular. De la misma manera argumentaba Robert Castel (1986) cuando decía que los sujetos dejan de ser tratados por los especialistas en detrimento de sus evaluaciones técnicas que van conformando los "historiales subterráneos" de los diagnósticos expertos que siguen la trayectoria vital del sujeto en las instituciones pronosticando su futuro en función de las probabilidades de ocurrencia de ciertos fenómenos futuros, pronósticos contrafácticos que no necesitan evidencia empírica para su comprobación, aunque signan la vida de quienes han sido etiquetados (cf. Goffman, [1963] 1995; Zaffaroni, 1989; Zaffaroni, Alagia \& Slokar, 2002).

La autopercepción del informe experto como discurso de verdad remite a la unidad de saber y poder referido por Foucault (2000), aunque algunos especialistas aparecerían cuestionando la utilización profana de las palabras técnicas en los escritos judiciales (González Laurino, 2014), deslindando, de esta forma su responsabilidad en la decisión que finalmente recaerá sobre el adolescente.

En este juego del desciframiento de la verdad los técnicos construirán sus informes en base a la trayectoria biográfica de los adolescentes, anticipando, en sus vulnerabilidades sociales, económicas y culturales, la concepción de un sujeto peligroso que ya estaba impresa en los múltiples abandonos de los que su biografía estaría dando cuenta. En este sentido, el adolescente es colocado a juicio tanto por la trasgresión cometida como por el informe experto, que confirmaría, una vez más, los rastros de trasgresiones sin ilegalidad impresas en las trayectorias vitales de estos adolescentes que estarían explicando, en el lenguaje experto, los motivos de la infracción a la ley penal por el que se los coloca bajo la lupa del tribunal y del especialista (Foucault, 2000).

En su análisis de las cárceles españolas, Elena Larrauri (2019) describe la psicologización del proceso de reeducación mediante una concepción teórico-metodológica cognitivo conductual sustentada en premios y castigos por actitudes y conductas en contextos de encierro que parecerían estar señalando un poder similar al de los informes técnicos sobre la justicia penal juvenil uruguaya. Al mismo tiempo llama la atención la similitud del caso uruguayo con el análisis de los informes técnicos de psicólogos y asistentes sociales en el caso del centro de privación de libertad adolescente en San Pablo (Lima \& Alvarez, 2018). Estas asociaciones en la descripción de

8. El paréntesis recto refiere a la primera edición de la obra. 
las mismas herramientas utilizadas en diversos escenarios, junto al análisis de análogas disyuntivas entre el personal custodial y los técnicos encargados de la elaboración de informes judiciales en distintos contextos nacionales, estaría hablando de tratamientos que se repiten en las instituciones de control social, con independencia del contexto en el que los conflictos se tramitan. En este sentido, es posible plantear como hipótesis que en los centros de encierro se plantean similares situaciones que reciben tratamientos metodológicos y disciplinarios parecidos.

Por otra parte, el relato de algunos entrevistados uruguayos estaría habilitando procesos de estímulo de conocimiento de sí mismo en los que medie el pensamiento y la palabra para transitar un proceso de autoapreciación y reconocimiento social con la guía de personas que promuevan procesos reflexivos, como expone Foucault en la etapa ética de su producción $(2001,2009,2010)$. Aunque marginales, estos espacios se abren como esperanzas de autoafirmación social en la vida de estos adolescentes, al menos en las medidas a medio abierto, ya que, como dice Sartre en la biografía de Genet, "nuestra certidumbre de nosotros mismos encuentra su verdad en el Otro cuando este nos reconoce" ([1952 $]^{9} 2005$, p. 69).

La construcción del sí mismo se ve seriamente cuestionada en condiciones de privación de libertad adolescente desde la perspectiva de la ética foucaultiana (2001, 2009, 2010), que solo puede ser pensada desde la lógica del castigo y el ejercicio de auto constricción y arrepentimiento indicado en el Código de la Niñez y la Adolescencia (Ley 17.823, 2004), defendido por los operadores judiciales y desarrollado en la práctica de los técnicos de ejecución de las medidas socioeducativas. Sin el "arrepentimiento" del infractor por la acción por la que fuera judicializado se abre la perspectiva de la "peligrosidad" como camino sin retorno que promueve un derecho basado en el actor y no en la acción trasgresora.

9. El paréntesis recto refiere a la primera edición de la obra. 


\section{Referencias}

AваL, Alicia et al. (2005), Adolescencia e infracción: una aproximación a la construcción subjetiva. Montevideo, Instituto del Niño y el Adolescente en Uruguay. Centro de Formación de Educadores Sociales.

American Psychological Association. (2017), Ethical principles of psychologists and code of conduct. Washington, DC, Autor.

Ávila Navarrete, Viviana. (2017), “¿Corresponsabilidad familiar en instituciones de reeducación para adolescentes infractores?". Revista Latinoamericana de Ciencias Sociales, Niñez y Juventud, 15 (2): 1191-1206. https://doi.org/10.11600/1692715x.1115080812, consultado en 10/05/2018.

Batthyány, Karina. (2008), "Pobreza y desigualdades sociales. Una visión desde el género”. Papeles de Población, 57: 193-207.

BECK, Ülrich. (2001), "Vivir nuestra propia vida en un mundo desbocado: individualización, globalización y política”. In: Giddens, Anthony \& Hutton, Will (orgs.). En el límite. La vida en el capitalismo global. Barcelona, Kriterios TusQuets Editores, pp. 233-246.

Becker, Howard. (2009), Outsiders. Hacia una sociología de la desviación. Buenos Aires, Siglo XXI.

Bourdieu, Pierre. (1994), "Rethinking the state: Genesis and structure of the bureaucratic field”. Sociological Theory, 12: 1-18.

Bourdieu, Pierre. (1987), “The force of law: Towards a sociology of the juridical field”. Hastings Law Journal, 38: 814-853.

Castel, Robert. (1986), “De la peligrosidad al riesgo". In: CAstel, Robert et al. Materiales de Sociología critica. Madrid, La Piqueta, pp. 219-243.

Christie, Nils. (1988), Los límites del dolor. México: Fundación de Cultura Económica.

Código De La Niñez Y La Adolescencia. (7 de septiembre de 2004), Ley n. 17.823. Publicado por el Boletín Oficial del Estado el 14 de septiembre de 2004. Impo. Centro de Información Oficial. Disponible en https://www.impo.com.uy/bases/codigo-ninez-adolescencia/17823-2004, consultado en: 21/01/2020.

Código Del Niño. (8 de febrero de 1934), Ley n. 9.342. Publicado por el Boletín Oficial del Estado el 2 de mayo de 1934. Impo. Centro de Información Oficial. Disponible en https:// www.impo.com.uy/bases/leyes/9342-1934, consultado en 21/01/2020.

Código Del Proceso Penal. (19 de diciembre de 2014), Ley n. 19.293. Publicado por el Boletín Oficial del Estado el 9 de enero de 2015. Impo. Centro de Información Oficial. Disponible en https://www.impo.com.uy/bases/codigo-proceso-penal-2017/19293-2014, consultado en 21/01/2020.

Código Penal. (4 de diciembre de 1933), Ley n. 9.155. Impo. Centro de Información Oficial. Disponible en https://www.impo.com.uy/bases/codigo-penal/9155-1933/197, consultado en $21 / 01 / 2020$. 
Crewe, Ben. (2011), "Soft power in prison: Implications for staff - prisoner relationships, liberty and legitimacy". European Journal of Criminology, 8 (6): 455-468.

Daroqui, Alcira \& López, Ana Laura. (2012), Sujeto de castigos. Hacia una sociología de la penalidad juvenil. Rosario, Homo Sapiens.

Donzelot, Jacques. (2008), La policía de las familias. Familia, sociedad y poder. Buenos Aires, Ediciones Nueva Visión.

EL PAÍs. Suplemento "Qué Pasa”. (2016), "Mismo problema, diferentes nombres. Sistema penal para adolescentes: el dilema de los mil nombres”. Publicado el 12 de setiembre de 2016. Disponible en https://www.elpais.com.uy/que-pasa/sistema-penal-adolescentes-dilema-mil-nombres.html.

Fiscalía General De La Nación. Uruguay. (2019), "Aumenta la eficiencia del nuevo proceso penal”. Disponible en http://www.fiscalia.gub.uy/innovaportal/v/8549/1/innova. front/aumenta-la-eficiencia-del-nuevo-proceso-penal.html, consultado en 15/03/2020.

Fiscalía General De La Nación. Uruguay. (2018), "Eficacia y eficiencia del sistema penal uruguayo durante el primer año del nuevo CPP: principales conclusiones". Montevideo, Departamento de Políticas Públicas de FGN. Disponible en http://www.fiscalia.gub.uy/ innovaportal/file/5980/1/sintesis-final-un-ano.pdf, consultado en 15/03/2020.

Foucault, Michel. (2010), El coraje de la verdad. Curso en el Collège de France (1983-1984). Buenos Aires, Fondo de Cultura Económica.

Foucault, Michel. (2009), El gobierno de síy de los otros. Curso en el Collège de France (19821983). Buenos Aires, Fondo de Cultura Económica.

Foucault, Michel. (2001), La hermenéutica del sujeto. Curso en el Collège de France (19811982). Buenos Aires, Fondo de Cultura Económica.

Foucault, Michel. (2000), Los anormales. Curso en el Collège de France (1974-1975). Buenos Aires, Fondo de Cultura Económica.

García Méndez, Emilio. (2017), Infancia. ¿Para dónde van sus derechos? Buenos Aires, Didot. García MÉndez, Emilio. (2004), Infancia de los derechos y de la justicia. Buenos Aires, Ediciones del Puerto.

García Méndez, Emilio. (2011), "La privación de libertad como forma de 'protección a la infancia': un caso paradigmático de construcción judicial de vulnerabilidad”. Espacio Abierto, 14: 57-64.

García Méndez, Emilio \& Carranza, Elías. (1990), "De la minoridad a la infancia-adolescencia: bases para una historia latinoamericana”. In: Infancia, adolescencia y control social en América Latina. Primer informe, San José de Costa Rica, 21 a 25 de agosto de 1989. Buenos Aires, Unicri, Ilanud, Depalma.

García MÉndez, Emilio et al. (2019), Historia y futuro de la cuestión penal juvenil. De Tejedor a Videla. Buenos Aires, Didot.

Garland, David. (2006), Castigo y sociedad moderna. Un estudio de teoría social. México, Siglo XXI. 
Guerra Henriques, Helder Manuel. (2014), “Marginalidade e reeducação de menores em Portugal: A Colónia de Vila Fernando (1880-1940)”. Estudios Humanísticos. Historia, 13: 145-164.

Goffman, Erving. (1995), Estigma. La identidad deteriorada. Buenos Aires, Amorrortu, 1995. González Laurino, Carolina. (2014), Los discursos expertos sobre la responsabilidad en la infracción adolescente. Montevideo, Comisión Sectorial de Investigación Científica. Universidad de la República.

González Laurino, Carolina \& Leopold Costábile, Sandra. (2013), “De crisis y reformas. $\mathrm{El}$ actual funcionamiento del sistema penal juvenil en Uruguay desde la perspectiva de sus actores y expertos". In: GonZÁLEZ LAURINo, Carolina et al. (orgs.). Los sentidos del castigo. El debate uruguayo sobre la responsabilidad en la infracción adolescente. Montevideo, Comisión Sectorial de Investigación Científica. Universidad de la República - Trilce, pp. 45-69.

González LaUrino, Carolina \& Leopold Costábile, Sandra. (2017), “La construcción del discurso de la responsabilidad en el sistema penal juvenil". In: Abella, Rosana y Fessler, Daniel (orgs.). El retorno del "estado peligroso". Montevideo, Casa Bertolt Brecht - Grupo de Estudios sobre infracción adolescente. Comisión Sectorial de Investigación Científica, Universidad de la República, pp. 53-75.

Guemureman, Silvia. (2011), La cartografia moral de las prácticas judiciales en los Tribunales de Menores. Los tribunales orales de la ciudad de Buenos Aires. Buenos Aires, Ediciones del Puerto. Halliday, Simon et al. (2009), "Street-Level Bureaucracy, Interprofessional Relations, and Coping Mechanisms: A Study of Criminal Justice Social Workers in the Sentencing Process". Law \& Policy, 31 (4): 405-428.

LARrAURI, Elena. (2019), "Reducing discretion in the administration of prison leave: In search of legitimacy”, European Journal on Criminal Policy and Research. Disponible en https:// doi.org/10.1007/s10610-019-09424-4, consultado en 11/03/2019.

Leal, Denise Maria \& Macedo, João Paulo. (2019), “Os discursos protetivos e punitivos acerca dos adolescentes em medida de internação no Brasil”. Revista Latinoamericana de Ciencias Sociales, Niñez y Juventud, 17 (1): 207-221. Disponible en https://dx.doi. org/10.11600/1692715x.17112, consultado en 11/02/2020.

Leopold, Sandra. (2002), Tratos y destratos. Prácticas públicas de atención a la infancia en Uruguay. Montevideo: Tesis de Maestría en Trabajo Social. Universidad Federal de Río de Janeiro - Universidad de la República.

LeOpold, Sandra. (2014), Los laberintos de la infancia: discursos, representaciones y critica. Montevideo, Comisión Sectorial de Investigación Científica, Universidad de la República. LEY n. 16.137, de 28 de septiembre de 1990 que ratifica la Convención de los Derechos del Niño. Publicado por el Boletín Oficial del Estado el 9 de noviembre de 1990. Impo. Centro de Información Oficial. Disponible en http://www.impo.com.uy/bases/leyes/16137-1990, consultado en: 21/01/2020. 
LEY n. 18.711, del 1 de julio de 2011. Creación del Sistema de Responsabilidad Penal Adolescente (Sirpa) como servicio transitorio dependiente del Instituto del Niño y el Adolescente del Uruguay. Publicado por el Boletín Oficial del Estado el 25 julio 2011. Impo. Centro de Información Oficial. Disponible en https://www.impo.com.uy/bases/leyes/18771-2011/1.

LEY n. 19.367, del 31 de diciembre de 2015. Creación del Instituto Nacional de Inclusión Social Adolescente (Inisa) como servicio descentralizado. Publicado por el Boletín Oficial del Estado el 27 enero 2016. Impo. Centro de Información Oficial. Disponible en https:// www.impo.com.uy/bases/leyes/19367-2015/11, consultado en 3/02/2020.

Lima, Juliana Vinuto \& Alvarez, Marcos César. (2018), “O adolescente em conflito com a lei em relatórios institucionais: pastas e prontuários do 'Complexo do Tatuapé' (Febem, São Paulo/sp, 1990-2006)”. Tempo Social, 30 (1): 233-257. Disponível em https://doi. org/10.11606/0103-2070.ts.2018.114545.

Lipsky, Michael. (1983), Street-level bureaucracy: dilemmas of the individual in public services. Nova York, Russell Sage Foundation.

Morais De Ramírez, Maria Gracia. (2018), Sanciones no privativas de libertad para adolescentes en Uruguay. Modelo de intervención. Montevideo, Poder Judicial, Fiscalía General de la Nación, Instituto del Niño y Adolescente del Uruguay (Inau), Instituto Nacional de Inclusión Adolescente (Inisa), Asociación Nacional de Organizaciones No Gubernamentales Orientadas al Desarrollo (Anong), Instituto Interamericano del Niño, la Niña y Adolescentes (IIN), Fondo de las Naciones Unidas para la Infancia (Unicef, Uruguay).

Morás, Luis Eduardo. (2002), Los hijos del Estado. Montevideo, Departamento de Sociología. Facultad de Ciencias Sociales. Universidad de la República - Servicio Paz y Justicia - Uruguay. MorÁs, Luis Eduardo. (2016), Estudio de las trayectorias de vida de adolescentes en conflicto con la ley con particular énfasis en la relación delito-trabajo. Montevideo, OIT, Cinterfor.

OrTega, Elizabeth. (2008), El servicio social y los procesos de medicalización de la sociedad uruguaya en el periodo neobatllista. Montevideo, Trilce.

Platt, Anthony. (1982), Los "Salvadores del Niño" o la invención de la delincuencia. México, Siglo XXI.

SARTre, Jean-Paul. (2005), San Genet, comediante y mártir. Buenos Aires, Losada.

Silva, Diego Balerio. (2001), "La acción educativa liberadora en contextos de control social. Buscando estrategias de disminución de la vulnerabilidad al sistema punitivo y de reducción de la violencia de las respuestas penales". In: Gadottr, Moacir (org.). Lecciones de Paulo Freire. Cruzando fronteras: experiencias que se completan. Buenos Aires, Clacso, pp. 225-257.

Silva, Diego Balerio. (2016), Estrategia nacional de educación para personas en conflicto con la ley penal. Grupo de trabajo Adolescentes. Montevideo, Unión Europea, Presidencia de la República, OIT-Cinterfor, Programa de Justicia e Inclusión.

Tenembaum, Gabriel. (2019), “¿Dónde está la causa de todos los problemas de la criminalidad nacional? Las propuestas del Partido Nacional sobre el sistema de responsabilidad 
penal adolescente". Brecha, 6 de setiembre de 2019. Edición 1763. Disponible en https:// brecha.com.uy/donde-esta-la-causa-de-todos-los-problemas-de-la-criminalidad-nacional, consultado en 6/12/2019.

URIARTE, Carlos. (1999), Control institucional de la niñez adolescencia en infracción. Un programa mínimo de contención y limites jurídicos al Sistema Penal Juvenil (las penas de los jóvenes). Montevideo, Carlos Álvarez Editor.

URIARTE, Carlos. (2006), Vulnerabilidad, privación de libertad de jóvenes y derechos humanos. Montevideo, Fundación de Cultura Universitaria - Centro de Formación y Estudios del Instituto del Niño y Adolescente del Uruguay.

URIARTE, Carlos. (2013), “La cuestión de la responsabilidad en el derecho penal juvenil”. In: González Laurino, Carolina et al. (orgs.). Los sentidos del castigo. El debate uruguayo sobre la responsabilidad en la infracción adolescente. Montevideo, Comisión Sectorial de Investigación Científica. Universidad de la República - Trilce, pp. 141-161.

ZafFaroni, Eugenio Raúl. (1989), En busca de las penas perdidas. Deslegitimación y dogmática jurídico-penal. Buenos Aires, Ediar.

Zaffaroni, Eugenio Raúl et al. (2002), Derecho Penal. Parte general. Buenos Aires, Ediar.

\section{Resumo}

Sentidos, práticas e modificações nos relatórios técnicos do sistema penal juvenil uruguaio

Mediante uma pesquisa qualitativa que combina a análise de relatórios judiciais e entrevistas, o artigo analisa a influência exercida pelos relatórios especializados sobre as decisões judiciais. Estuda-se a receptividade dessas peças discursivas nos Tribunais de Adolescentes de Montevidéu e aborda-se a influência da descrição das biografias dos adolescentes, como se as trajetórias de vida dos sujeitos explicassem os motivos da conduta transgressora à lei penal e previssem o seu futuro, em uma espécie de prognóstico contrafactual de riscos, impossível de verificação empírica e inextricavelmente associado à concepção de periculosidade.

Palavras-chave: Relatórios especializados; Prognósticos; Periculosidade; Trajetórias biográficas; Sistema penal juvenil. 


\section{Resumen}

Sentidos, prácticas y modificaciones en los informes técnicos del sistema penal juvenil uruguayo A través de una investigación cualitativa que combina análisis de expedientes judiciales y de entrevistas, este artículo analiza la influencia de los informes expertos sobre las decisiones judiciales. Se estudia la receptividad de estas piezas discursivas en los Juzgados de Adolescentes de Montevideo, dando cuenta de la influencia de la descripción de las biografías adolescentes como si las trayectorias de vida de los sujetos explicaran los motivos de la conducta trasgresora a la ley penal, prediciendo su futuro, en una suerte de pronóstico contrafáctico de riesgos, imposible de verificación empírica, inextricablemente asociado a la concepción de peligrosidad.

Palabras-clave: Informes expertos; Pronósticos; Peligrosidad; Trayectorias biográficas; Sistema penal juvenil.

\section{Abstract}

Meanings, practices, and modifications in juridical technical reports of Uruguayan juvenile penal system

Through qualitative research that combines analysis of judicial records and interviews, this article analyses the influence of expert reports on judicial decisions. The receptivity of these discursive pieces in the Juvenile Courts of Montevideo is studied, giving account of the influence of the description of the adolescent biographies as if the life trajectories of the subjects explained the motives of the transgressive conduct to the penal law, predicting its future, in a kind of counterfactual forecast of risks, impossible to empirically verify, inextricably associated with the concept of dangerousness.

Keywords: Expert reports; Forecasts; Dangerousness; Biographical trajectories; Juvenile penal system.

Texto recebido em 17/7/2020 e aprovado em 1/2/2021.

DOI: 10.11606/0103-2070.ts.2021.172532.

Carolina González Laurino é doutora em Sociologia e Ciências Políticas, professora titular do Departamento de Trabajo Social da Facultad de Ciencias Sociales da Universidad de la República de Uruguay. Coeditora da revista Fronteras, do Departamento de Trabajo Social de la Facultad de Ciencias Sociales de la Universidad de la República. Pesquisadora do Sistema Nacional de Investigadores (SNI) da Agencia Nacional de Investigación e Innovación (ANII). E-mail: carolsoc@gmail.com. 